\title{
La transformación del paisaje en la antigua turbera de Saldropo. 25 años de seguimiento y de casi no intervención
}

\author{
Dra. Barraqueta, P. ${ }^{1,2}$, Heras, P. ${ }^{1,3}$, Dra. Infante, M. ${ }^{1,3}$, Elosegi, M. ${ }^{2}$, Prieto, A. ${ }^{1}$, Bela- \\ mendia, G. ${ }^{4}$, Ruiz de Infante, J. ${ }^{1}$, Maestro, D. ${ }^{1}$, Potes, E. ${ }^{5}$, Tejado, C. ${ }^{5}$ \\ ${ }^{1}$ Miembros de SALDROPO, Grupo para el Estudio y la Protección de los Humedales Continentales. \\ ${ }^{2}$ EKOS, Asesoría e Investigación Medioambiental ekos@ekos-eeco.com \\ ${ }^{3}$ Museo de Ciencias Naturales de Álava bazzania@arrakis.es \\ ${ }^{4}$ Centro de Estudios Ambientales de Vitoria (Álava). \\ ${ }^{5}$ Instituto Alavés de la Naturaleza (Vitoria-Álava).
}

\section{Resumen}

El actual Humedal de Saldropo, de 5,7 hectáreas, es fruto de un proceso de regeneración natural e integración paisajística de una antigua turbera acometido a principios de los años 90. Tras el cese de las actividades extractivas, el área quedó convertida en un solar de terrenos removidos, sin apenas vegetación, con depresiones con agua y montículos de tierra y escombros. Siendo ya imposible la recuperación del ecosistema de turbera, se optó por acometer un proyecto de renaturalización con una mínima intervención humana, limitada a vallar el área de actuación para evitar la entrada del ganado e incrementar las láminas de agua mediante un cierre puntual del sistema de drenaje. En poco tiempo, el crecimiento vegetal disimuló la perturbación ecológica y paisajística sufrida y se desarrolló un sistema húmedo mixto, con áreas secas, estanques y un bosque pantanoso, destacando la llamativa proliferación de la sauceda (Salix atrocinerea) que se desarrolla sobre suelos más o menos encharcados, con helechos en el sotobosque y una interesante comunidad muscinal corticícola. En cada uno de estos ambientes, se constató un paulatino enriquecimiento de especies florísticas y faunísticas. En este momento, 25 años más tarde del inicio de la intervención se reconocen seis unidades de vegetación: sauceda, pastos, juncales, zarzal-helechal, cañaveral y masas de vegetación flotante. Veinte especies de mamíferos frecuentan el humedal (12 de meso y macromamíferos y 8 de micromamíferos). En el interior del recinto vallado se han inventariado 6 especies de anfibios y 6 de reptiles. Las especies de aves que visitan el humedal o han sido avistadas en su área de influencia ascienden a 52.

Palabras clave: restauración ecológica, Salix atrocinerea, humedal, sauceda, Zeanuri, País Vasco. 


\section{Introducción}

Los humedales son clave para la conservación de los hábitats y las especies, constituyendo indicadores básicos de la calidad y salud del medio natural. Entre la extraordinaria diversidad de humedales, destacan por su singularidad las turberas, medios palustres formadores de depósitos de turba que constituyen "registros históricos" de los climas y los paisajes del pasado. En la Península Ibérica, las turberas son hábitats relícticos que albergan procesos biológicos y geoquímicos únicos, además de acoger una flora y fauna sumamente especializadas. A pesar de su extraordinario valor, las turberas se han ido desecando para aprovechamientos ganaderos o agrícolas y la explotación de la turba para su uso como combustible y mejorante agrícola. En esta línea de gestión de las turberas, a finales de los años ochenta del pasado siglo se produjo la explotación intensiva final de la turbera de Saldropo para el aprovechamiento de su turba como sustrato de jardinería y, con ello, la consiguiente desaparición de la misma, el único caso de turbera elevada de la Comunidad Autónoma del País Vasco. Tras el cese de la explotación, se abordó un proyecto de restauración con el objetivo de devolver al lugar el carácter de humedal que tuvo. Tras más de 25 años de proceso restaurativo, el área se ha transformado en el Humedal de Saldropo, un biotopo que poco tiene que ver con el extinto sistema turboso, pero que a pesar de su breve historia no carece de excelentes valores naturales.

\section{Metodología}

El actual Humedal de Saldropo, se ubica en el macizo del Gorbea, dentro de los límites del Parque Natural de Gorbeia, en el término municipal de Zeanuri (Bizkaia, España), a unos $2 \mathrm{~km}$ al SW del Puerto de Barazar (carretera N-240). Una pista permite el acceso, tanto al humedal como a la vecina Área Recreativa de Saldropo. Las coordenadas de referencia (WGS84) son 30T 522284_4766597 y la altitud unos 625 m s.n.m. El área de actuación comprende alrededor de 5,7 hectáreas, abarcando la superficie ocupada por la antigua Turbera de Saldropo más alguna zona anexa.

La información referente a la turbera puede encontrarse en Ugarte et al. 1986, García Antón et al. 1987 y 1989, Infante \& Heras 1987a y b, Peñalba 1988 y Heras 1992.

Tras el cese de las labores extractivas, quedó un paisaje desolador de terrenos removidos y prácticamente desprovistos de vegetación, generadores de un impacto visual y paisajístico muy negativo (fig. 1). Destacaban los montículos de escombros y estériles, intercalados con balsas y zanjas con agua. Puntualmente, se mantuvieron pequeñas manchas arbóreas de robledal, así como pies aislados de robles (Quercus robur), piruétanos (Pyrus cordata), espinos (Crataegus monogyna) y, sobre todo, acebos (Ilex aquifolium), muchos de ellos fueron trasplantados durante la explotación de turba.

Conscientes de su valor naturalístico, y partiendo de una iniciativa particular, el Departamento de Agricultura de la Diputación Foral de Bizkaia inició en 1990 las 

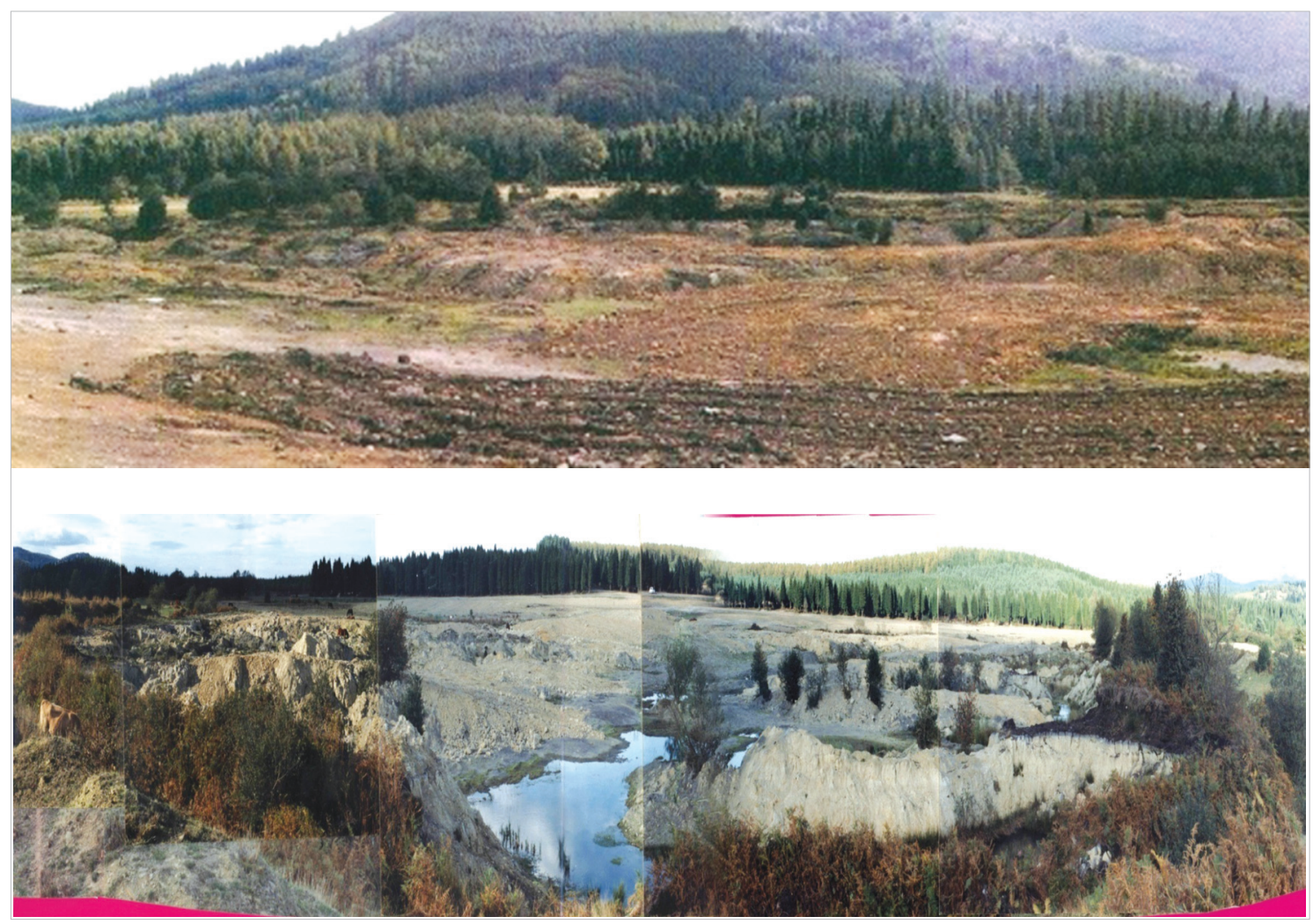

Figura 1. Estado de los terrenos a restaurar tras el cese de la explotación de la Turbera de Saldropo (1990). $\mathrm{Al}$ fondo en la fotografía superior, la "ceja de turba".

primeras medidas de restauración del lugar. Ya para entonces se observaba una primera colonización de las balsas, principalmente por juncos (Juncus effusus) espadañas (Typha latifolia) y platanarias (Sparganium erectum) (fig. 2).
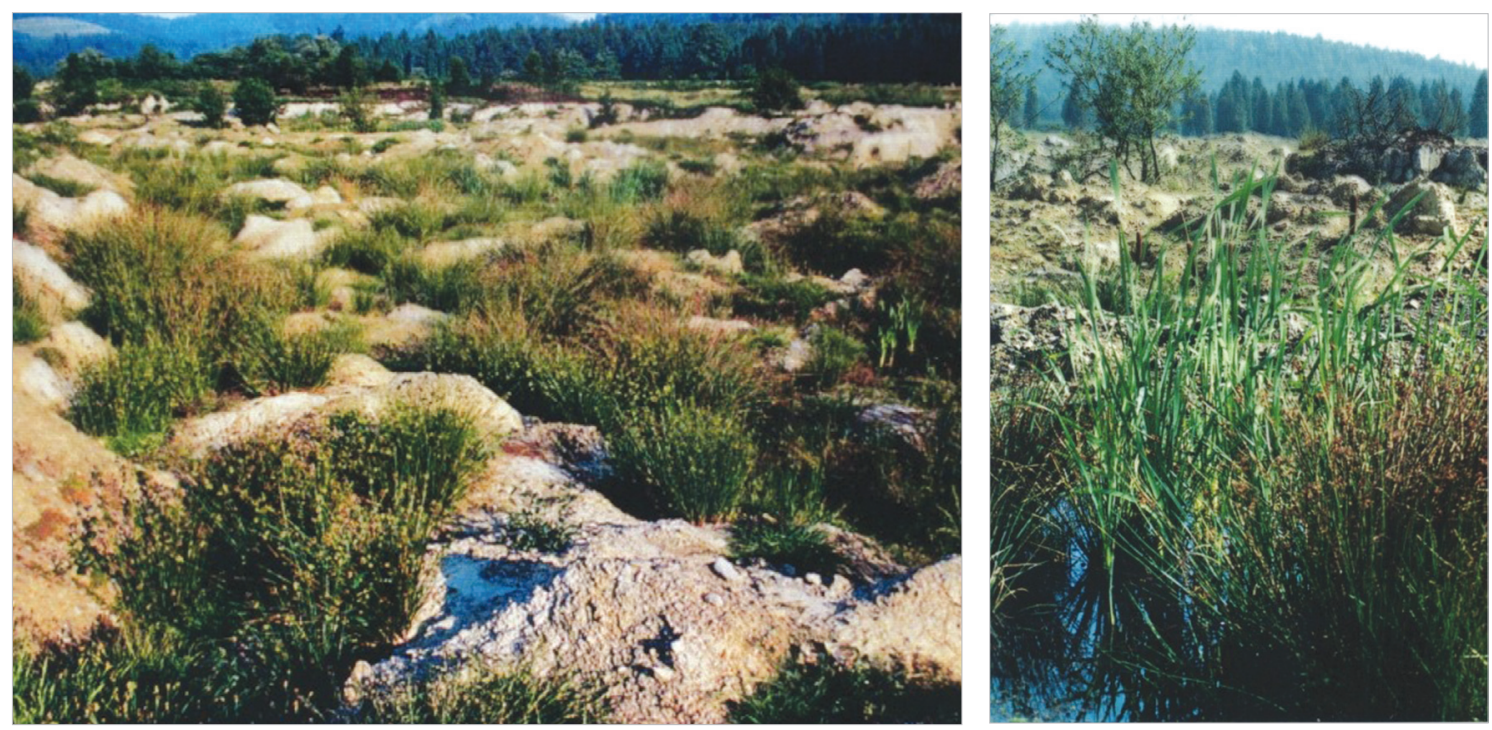

Figura 2. Juncos y espadañas colonizando las zonas más húmedas de Saldropo (1990). 
Puesto que la explotación de la turbera conllevó la práctica destrucción del depósito de turba (excepto una reducida "ceja de turba" que ha quedado como testigo), la recuperación del ecosistema turboso original era del todo inviable, optándose por la renaturalización del lugar bajo dos objetivos generales:

- Restauración ecológica, tratando de convertir el área alterada en un humedal.

- Restauración paisajística.

El criterio de la acción restaurativa fue favorecer la recuperación espontánea, dejando actuar a la sucesión natural y efectuando las mínimas intervenciones:

- Cierre de los drenajes para aumentar la lámina de agua. Se construyó un pequeño dique en el extremo oriental, sobre la zanja de drenaje perimetral a la antigua turbera, con el fin de elevar el nivel general de inundación.

- Vallado perimetral del área de actuación. El objetivo era evitar la entrada del ganado, que es abundante y pasta libremente en los prados inmediatos, tratando de evitar su interferencia en el proceso renaturalizador.

- Plantación de un reducido número de abedules, alisos y arbustos autóctonos, tanto en el perímetro del área de actuación, a modo de pantalla de protección, como en ciertas zonas del interior del recinto, para acelerar el proceso de recuperación.

- Aplanado de algunos de los montículos de estériles. Esta medida sólo se realizó en determinadas zonas, para favorecer el desarrollo de ciertas balsas, evitando hacer retroceder el proceso renaturalizador espontáneo que ya se había iniciado (fig. 2).

A lo largo del tiempo, desde el inicio del proceso de renaturalización en 1990, se han realizado reconocimientos del estado del humedal para constatar las transformaciones ambientales y los cambios acontecidos en diferentes grupos faunísticos y botánicos (1990-1997). En 1999, se elaboró una primera cartografía de la vegetación (Prieto et al. 1999). En 2012 se realizó un nuevo reconocimiento y elaboró una cartografía actualizada. Cartografía que se volvió a revisar en 2014-2015, actualizando la ubicación de las charcas e inventariando las especies de flora, aves, mamíferos, anfibios y reptiles presentes en Saldropo.

\section{Resultados}

Con la explotación de la Turbera de Saldropo, la vegetación propia de turberas desapareció en su totalidad al perderse el sustrato turboso que la sustentaba. En la actualidad, el biotopo que la ha sustituido (Humedal de Saldropo) presenta el aspecto de un ambiente arbolado, muy diferente al de la turbera original y al paisaje de partida en el año 1990 (fig. 3).

Al poco tiempo de iniciar el proyecto de renaturalización pudo comprobarse la respuesta del lugar a las medidas adoptadas: 


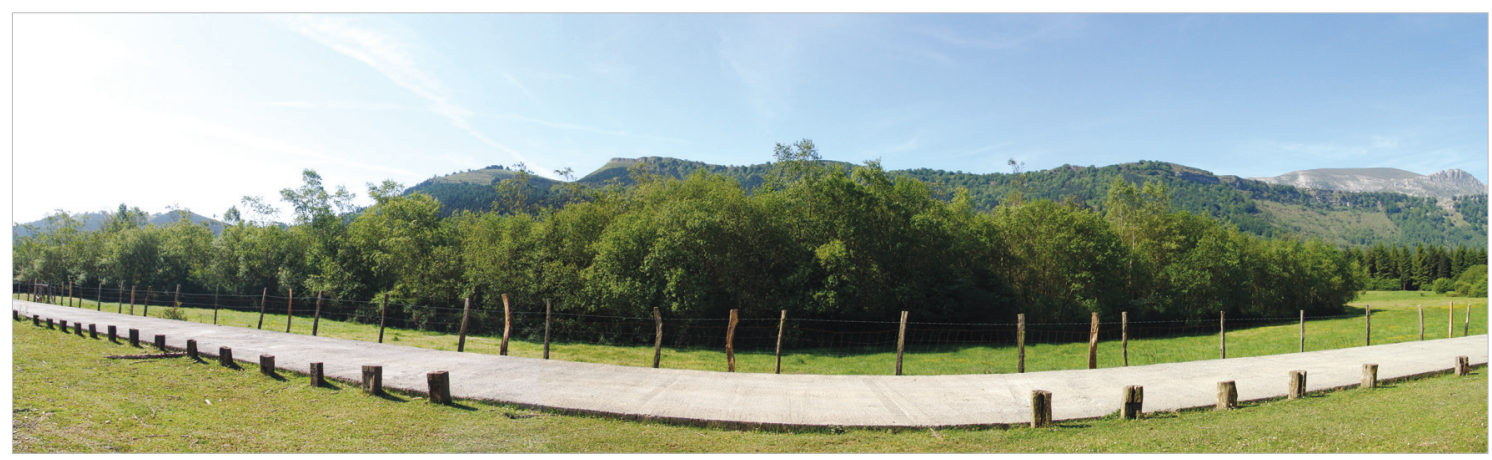

Figura 3. Aspecto boscoso del Humedal de Saldropo en 2014.

- Persistencia de parte de las balsas. A pesar de que en la mayoría se produce un descenso estival del nivel de inundación, desde el principio fueron colonizadas por helófitos (Typha latifolia y Sparganium erectum sobre todo). Esta estacionalidad en los niveles de agua introdujo heterogeneidad ambiental y favoreció la diversidad biológica. En 2015, en muchas de las charcas el proceso de colmatación y de colonización vegetal es muy notable por vegetación flotante, juncales y cañaverales, situación que también repercute en la composición de determinadas especies faunísticas.

- El vallado perimetral ha permitido al lugar evolucionar libre de la presencia del ganado, aunque puntualmente se detecta alguna entrada de ganado sin consecuencias aparentes. Se creó así una zona de refugio para la fauna, en la que los animales silvestres encuentran un ambiente tranquilo aislado de molestias. Estudios efectuados en los primeros años de renaturalización mostraron una sorprendente recuperación de la fauna, tanto en invertebrados (con un espectacular aumento de Odonatos) como en vertebrados, con nueve especies de anfibios, trece de macro y mesomamíferos y quince de micromamíferos. Ya en los primeros años del proceso renaturalizador se detectó la nidificación del zampullín común (Tachybaptus ruficollis) y la presencia de la gallineta común (Gallinula chloropus) y el rascón (Rallus aquaticus), sin embargo en 2015 no se ha detectado su presencia. El Humedal de Saldropo funciona además como zona de reposo y alimentación para la avifauna migradora europea

- La pantalla protectora, creada con la plantación de arbolado en el perímetro del área de actuación, también contribuyó a crear este ambiente tranquilo y libre de perturbaciones antrópicas. Con los años, este arbolado ha crecido aumentando la impresión de área boscosa que se percibe desde el exterior (fig.3).

- La irregularidad del terreno, con montículos y zonas deprimidas llenas de agua, produjo variedad de hábitats, lo cual favoreció la colonización por diversas especies animales y vegetales y, consecuentemente, un aumento de la biodiversidad inicial. 
Los resultados obtenidos a lo largo de los años de proyecto renaturalizador, así como las transformaciones que han ido sucediéndose en el Humedal de Saldropo, están recogidos en publicaciones e informes inéditos (EKOS 1991, Belamendía et al. 1997, Barraqueta et al. 1997, Barraqueta et al. 1999, Prieto et al. 1999, Barraqueta et al. 2012 y EKOS 2015).

La colonización vegetal, tras el cese de las actividades extractivas de turba, ha sido el factor clave en el éxito de la transformación paisajística y naturalística del lugar. Antes de pasar diez años de iniciarse el proyecto restaurativo, ya se habían detectado 113 taxones vegetales, entre cormófitos y briófitos (Belamendia et al. 1997, EKOS 1991). Sin duda alguna, la especie vegetal que se ha visto más favorecida por la renaturalización de Saldropo es el salguero negro (Salix atrocinerea), que ha ido ganando espacio a otras comunidades vegetales hasta hacerse dominante. Esta sauceda brinda el ambiente nemoral que especies propias de bosques húmedos necesitan y que poco a poco han ido apareciendo en Saldropo. La maduración de la sauceda ha favorecido la presencia de helechos (sobretodo Dryopteris affinis y Blechnum spicant, destacando la presencia de algunos escasos ejemplares de Osmunda regalis) y ha permitido la proliferación de musgos y hepáticas epífitas en los troncos, entre ellos alguna especie de interés como la hepática Metzgeria violacea, cuya presencia en la Península Ibérica se limita a la franja cantábrica (Infante 2000) y especies de musgos poco frecuentes en la Comunidad Autónoma del País Vasco como Orthotrichum pulchellum (especie Vulnerable dentro de la brioflora española) y Neckera pumila.

Entre las plantas vasculares, son muy escasas las especies de turbera que han regresado (Carex echinata, Hypericum elodes, Potamogeton polygonifolius). Ahora dominan plantas de humedales más eútrofos (como Baldellia ranunculoides, Carex flacca, C. cuprina, Eleocharis palustris, las mismas espadañas y platanarias) e incluso nemorales (como Carex pendula o los helechos ya mencionados). Todas ellas, se vieron favorecidas por la liberación de nutrientes que provocó la remoción de tierras durante los trabajos de explotación. Se formaron así comunidades vegetales muy diferentes de aquellas de carácter acidófilo y oligotrófico propias de turberas.

Durante todo este tiempo, ha aparecido alguna especie vegetal invasora, como Baccharis halimifolia y Cortaderia selloana, pero no presentan problemas, al tratarse de apariciones muy puntuales en el margen septentrional del humedal y de localizaciones fuera de su área de distribución principal que se hallan bajo condiciones ambientales desfavorables. Mayor presencia tienen dos coníferas exóticas, el ciprés de Lawson (Chamaecyparis lawsoniana) y el alerce japonés (Larix kaempferi) que se han extendido entre la sauceda, procedentes de las repoblaciones forestales del entorno de Saldropo. Actualmente, se ha procedido a la tala de gran parte de los cipreses y de algunos alerces.

En el Humedal de Saldropo, se han reconocido nueve formaciones vegetales diferentes (Prieto et al. 1999). Dichas formaciones y los cambios acaecidos en el humedal desde la primera cartografía de la vegetación en 1999 y el reconocimiento efectuado en 2012, quedan reflejados en el diagrama siguiente. 


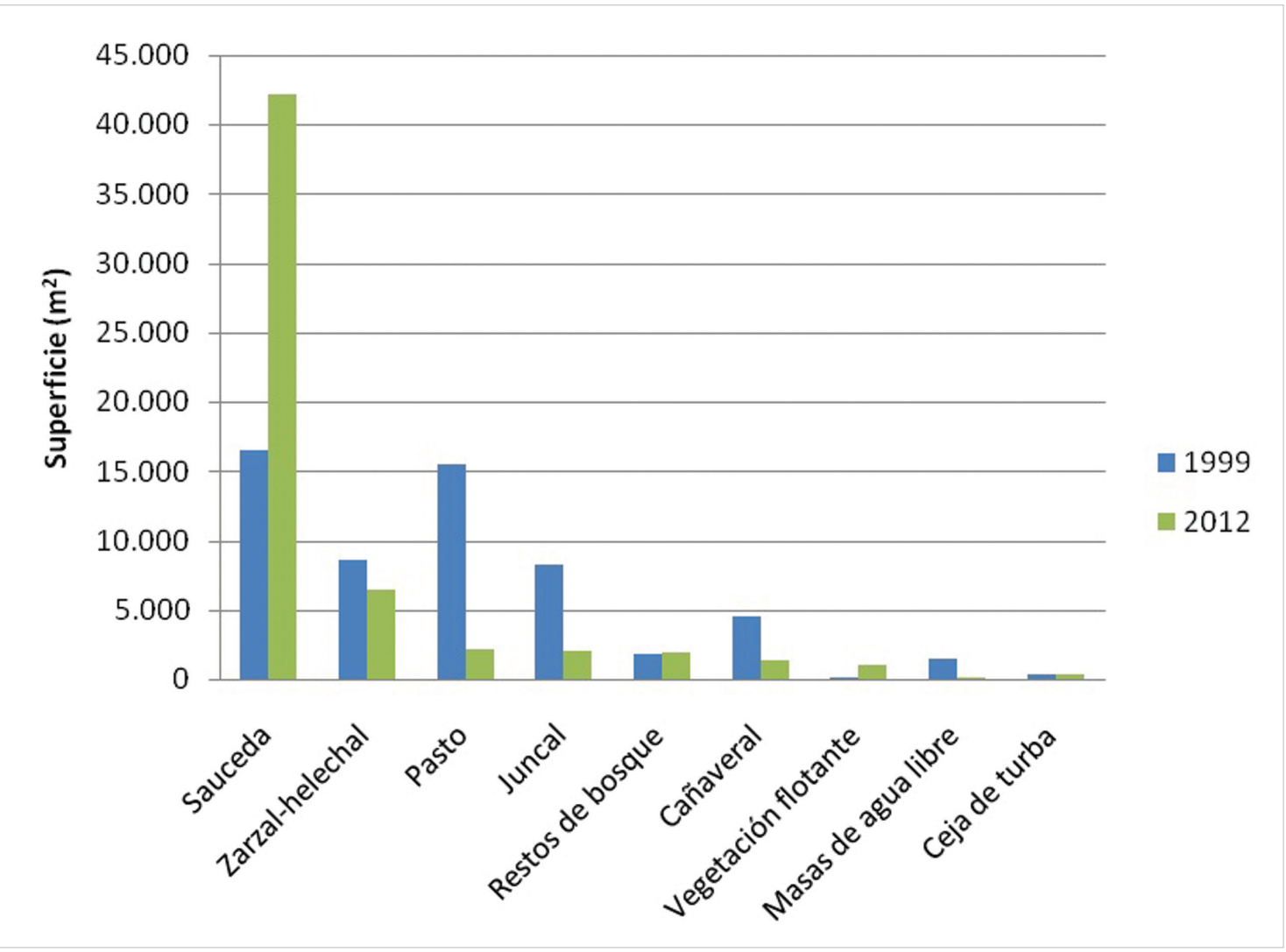

Figura 4. Variación de las unidades de vegetación entre 1999 y 2012 en el Humedal de Saldropo.

La sauceda de Salix atrocinerea es en estos momentos la comunidad vegetal dominante, superando en bastante más del doble la superficie ocupada en 1999. Es una formación que presenta bastante heterogeneidad, ya que ocupa desde suelos encharcados hasta los moderadamente secos, apareciendo en éstos últimos abedules $(\mathrm{Be}$ tula alba) que localmente se pueden hacer bastante abundantes y coníferas exóticas (sobre todo Chamaecyparis lawsoniana y Larix kaempferi). Su expansión ha sido a costa del pasto, la formación vegetal que mayor pérdida de superficie ha tenido desde 1999 y del juncal. También han disminuido su área de ocupación, aunque en mucha menos medida, el cañaveral y el zarzal - helechal. No experimentan variación los restos de bosque, pequeñas manchas del bosque original que existían previamente a la explotación de la turbera. Son comunidades de robledal de Quercus robur con mucho acebo y piruétano (Pyrus cordata), existiendo de este último algunos grandes ejemplares dignos de mención.

Especial mención merece la unidad denominada como "ceja de turba", que se corresponde con el resto-testigo que queda de la extinta Turbera de Saldropo (apenas un metro de espesor de turba, oculto por el arbolado). Aunque la superficie que ocupa sobre la cartografía es la misma que en 1999, los procesos de oxidación de la turba y la erosión van haciéndola desaparecer, lenta pero inexorablemente. Este proceso de pérdida se ve incluso acelerado por los animales (tejones, zorros) que exca- 
van aquí sus madrigueras. No alberga ningún rastro de la vegetación original de la turbera, pero su principal valor e interés es el de constituir el único vestigio que nos queda del registro histórico (paleoclimático y paleoecológico) que conservaba la Turbera de Saldropo.

A futuro, se prevé que en el Humedal de Saldropo se consolide y mantenga el proceso de maduración de la sauceda. A pesar de esta preponderancia de la vegetación arbórea, parece ser que se mantendrán algunas de las formaciones abiertas. Aunque puede que las áreas ocupadas por el pasto y el juncal acaben formando parte de la sauceda, la persistencia de ciertos estanques permite pensar que la vegetación flotante, y quizás también los cañaverales, perduren al menos durante bastante tiempo.

Para forzar una mayor naturalidad de la sauceda, se han eliminado gran parte de las coníferas exóticas que han invadido el humedal. Su madera se ha dejado en el lugar para favorecer el desarrollo de comunidades saprolignícolas, en especial de coleópteros y hongos.

Con respecto al inventario faunístico realizado en el año 1997, se observa en 20142015 una disminución del número de especies, excepto para el grupo de los reptiles (tabla 1). Ello es probablemente debido a la expansión de la sauceda que conlleva una homogenización del biotopo. Veinte especies de mamíferos frecuentan el humedal (12 de meso y macromamíferos y 8 de micromamíferos). En el interior del recinto vallado se han inventariado 6 especies de anfibios y 6 de reptiles. Las especies de aves que visitan el humedal o han sido avistadas en su área de influencia ascienden a 52 (tablas 2, 3 y 4).

Tabla 1. Número de especies de diferentes comunidades faunísticas en el Humedal de Saldropo en 1990, 1997 y 2014-2015.

\begin{tabular}{|c|c|c|}
\hline \multirow{2}{*}{} & \multicolumn{2}{|c|}{$\mathbf{N}^{\mathbf{0}}$ de especies } \\
\cline { 2 - 3 } & $\mathbf{1 9 9 7}$ & $\mathbf{2 0 1 4 - 1 0 1 5}$ \\
\hline Meso y macromamíferos & 13 & 12 \\
\hline Micromamíferos & 15 & 8 \\
\hline Anfibios & 9 & 6 \\
\hline Reptiles & 4 & 6 \\
\hline Aves & 56 (año 1990) & 52 \\
\hline
\end{tabular}

Tabla 2. Especies de anfibios y reptiles inventariados en el Humedal de Saldropo en 2014-2015.

\begin{tabular}{|l|l|}
\hline Anfibios & Reptiles \\
\hline Tritón jaspeado (Triturus marmoratus) & Lagarto verde (Lacerta bilineata) \\
\hline Tritón alpino (Mesotriton alpestris) & Lagartija parda (Podarcis liolepis) \\
\hline Tritón palmeado (Lissotriton helveticus) & Lagartija roquera (Podarcis muralis) \\
\hline Sapo partero común (Alytes obstetricans) & Lagartija de turbera (Zootoca vivípara) \\
\hline Rana bermeja (Rana temporaria) & Culebra de collar (Natrix natrix) \\
\hline Rana común (Pelophylax perezi) & Víbora cantábrica (Vipera seoanei) \\
\hline
\end{tabular}


Tabla 3. Especies de aves que predominan en el Humedal de Saldropo (2014/2015).

\begin{tabular}{|c|}
\hline Aves \\
\hline Corneja común (Corvus corone) \\
\hline Herrerillo común (Cyanistes caeruleus) \\
\hline Petirrojo (Erithacus rubecula) \\
\hline Pinzón vulgar (Fringilla coelebs) \\
\hline Mosquitero común (Phylloscopus collybita) \\
\hline Camachuelo común (Pyrrhula pyrrhula) \\
\hline Reyezuelo listado (Regulus ignicapilla) \\
\hline Mirlo común (Turdus merula) \\
\hline Zorzal común (Turdus philomelos) \\
\hline
\end{tabular}

Tabla 4. Especies de mamíferos inventariados en el Humedal de Saldropo en 2014/2015.

\begin{tabular}{|l|l|}
\hline Meso y macromamíferos & Micromamíferos \\
\hline Ciervo (Cervus elaphus) & Musaraña tricolor (Sorex coronatus) \\
\hline Corzo (Capreolus capreolus) & Musaraña gris (Crocidura russula) \\
\hline Jabalí (Sus scrofa) & Musgaño patiblanco (Neomys fodiens) \\
\hline Tejón (Meles meles) & Musaraña enana (Sorex minutus) \\
\hline Zorro (Vulpes vulpes) & Topillo agreste (Microtus agrestis) \\
\hline Garduña (Martes foina) & Ratón de campo (Apodemus sylvaticus) \\
\hline Comadreja (Mustela nivalis) & Rata negra (Rattus rattus) \\
\hline Gineta (Genetta genetta) & \multirow{2}{|}{ Topillo rojo (Clethrionomys glareolus) } \\
\hline Liebre europea (Lepus europaeus) \\
\cline { 1 - 1 } Topo común (Talpa europaea) \\
\cline { 1 - 1 } Erizo europeo (Erinaceus europaeus) \\
\cline { 1 - 1 } Ardilla roja (Sciurus vulgaris)
\end{tabular}

\section{Conclusiones}

La evolución de la renaturalización del Humedal de Saldropo ha sido seguida a lo largo de más de veinticinco años, comprobándose su sorprendente transformación -a partir del espacio de suelos removidos y desprovisto de vegetación que dejó la explotación de la turbera- en un ambiente boscoso húmedo en el que predomina la sauceda y que denota claramente la vocación forestal que tiene el lugar. En este contexto, señalar que los datos históricos muestran que hace milenios existió allí un bosque turboso de abedules, antes de que se desarrollara la turbera ombrogénica que hubo en un pasado no muy lejano en Saldropo (Heras 1992).

En esta sauceda, se intercalan formaciones vegetales hidrófilas en torno a pequeños estanques y depresiones $\mathrm{y}$, aunque aún persisten comunidades pioneras (pastos y zarzales - helechales), la sauceda ha ido extendiéndose hasta ser en la actualidad 
la formación dominante. Esta evolución va asociada con cierta homogenización ambiental. Señalar como aspecto negativo, la aparición de unas pocas plantas invasoras, así como la propagación de coníferas exóticas presentes en las repoblaciones del entorno, aunque gran parte de ellas se han talado recientemente.

A lo largo de todo este tiempo, se ha dado un proceso de sucesión ecológica entre especies arbóreas, ya que los abedules -que en su momento se plantaron- se están muriendo mientras que los sauces se desarrollan a buen ritmo. En aquellos sitios de suelo no encharcado, van apareciendo jóvenes pies de roble y también de manera abundante acebo, espino blanco y endrino.

Se mantienen y destacan dentro de la vegetación arbórea del humedal, los majestuosos ejemplares de piruétanos (Pyrus cordata), así como los grandes acebos (Ilex aquifolium) que fueron trasplantados a los montículos creados durante la explotación de la turbera y los que persisten entre los restos de bosque que ya existían en los últimos tiempos de la turbera.

Tras más de 25 años de renaturalización, unas pocas especies propias de la vegetación de turbera han reaparecido y ha aumentado espectacularmente el número de especies florísticas. Por contra, aunque Saldropo sigue siendo un refugio para la fauna, se ha producido una relativa disminución de la biodiversidad faunística, debido seguramente al predominio de la sauceda que conlleva una homogeneización del biotopo y a la progresiva colmatación de charcas, produciendo con ello cambios en la composición de la biocenosis.

Las perspectivas futuras contemplan potenciar la maduración de la sauceda húmeda que de forma espontánea se ha desarrollado, tratando de favorecer el encharcamiento del suelo, aumentando la altura del dique en el extremo oriental de la antigua zanja de drenaje perimetral de la turbera y manteniendo la naturalidad del lugar a través de intervenciones poco agresivas. Esta mayor lámina de agua amortiguará el descenso del anegamiento durante el estío que actualmente se observa y favorecerá a las comunidades estrictamente propias de humedales.

Por otra parte, también parece oportuno llevar a cabo alguna pequeña intervención para controlar la expansión de la sauceda porque va en detrimento de los espacios abiertos (charcas, áreas más soleadas, etc.) en aras de favorecer una mayor diversidad faunística.

Las medidas a adoptar deben, asimismo, contemplar la conservación de la "ceja de turba", único vestigio de la extinta Turbera de Saldropo.

\section{Agradecimientos}

Este trabajo ha sido financiado por el Ministerio de Economía y Competitividad (Plan Nacional I+D+i, ref. AGL2010-16575 y CTQ2013-46804-C2-1-R), por los fondos FEDER de la UE y por la empresa ENCE, energía y celulosa S.A. Contó con el apoyo del Campus de Excelencia Internacional CEI Cambio. 


\section{Referencias}

Barraqueta, P., Heras, P. \& Infante, M. (1997). La restauración de la antigua turbera de Saldropo. II Congreso de Ingeniería del Paisaje: 131-135. La Coruña.

Barraqueta, P., Heras, P. \& Infante, M. (1999). Saldropo: Vom Moor zum Feuchtgebiet. Bodenëkologie interdisziplinär, H. Koehler, K. Mathes \& B. Breckling (Hrsg.), Springer Verlag: 189-198.

Barraqueta, P., Heras, P. \& Infante, M. (2012). El Humedal de Saldropo: 22 años de renaturalización tras la explotación de la antigua turbera. Cascais World Forum 2012. Soil Bioengineering and Land Management-New Challenges. Proceedings Mayo 2014, 219230.

Belamendía, G., Galarza, A., Heras, P., Infante, M., Marcos, J.Ma , Olano, I. \& Tejado, C. (1997). Evolución de la Fauna y de la Flora en el Humedal de Saldropo. Informe inédito. EKOS, Asesoría e Investigación Medioambiental.

EKOS (1991). El Humedal de Saldropo. Informe inédito. EKOS, Asesoría e Investigación Medioambiental. Departamento de Agricultura. Diputación Foral de Vizcaya.

EKOS (2015). Seguimiento florístico, faunístico y paisajístico del Humedal de Saldropo. Informe inédito. EKOS Asesoría e Investigación Medioambiental. Departamento de Sostenibilidad y Medio Natural. Diputación Foral de Bizkaia.

García Antón, M., Ruiz Zapata, M.B. \& Ugarte, F.M. (1987). Primeros resultados del análisis geomorfológico - palinológico de la turbera de Saldropo (Alto de Barazar, Bizkaia). Comunicación de la VII Reunión sobre el Cuaternario AEQUA. Santander: 27-30.

García Antón, M., Ruiz Zapata, M.B. \& Ugarte, F.M. (1989). Análisis geomorfológico y palinológico de la turbera de Saldropo (Barazar. Zeanuri/ Bizkaia). Lurralde, 12: 25-44.

Heras, P. (1992). Caracterización y niveles del depósito orgánico de la turbera de Saldropo (Ceánuri, Vizcaya). The Late Quaternary in the Western Pyrenean Region. International Conference. Cearreta, A. \& Ugarte, F.M. (eds.): 343-351.

Heras, P. \& Infante, M. (2001). Hacia una lista roja de los briófitos (musgos y hepáticas) de la Comunidad Autónoma Vasca. Jornadas sobre Conservación y Gestión de Especies Amenazadas (28 de Febrero - 1 y 2 de Marzo de 2001, Vitoria - Gasteiz): 355-363.

Herrera Gallastegui, N. \& Campos Prieto, J.A. (2010). Flora alóctona invasora de Bizkaia. Diputación Foral de Bizkaia. 196 pp.

Infante, M. \& Heras, P. (1987a). Estudio briológico de la turbera de Saldropo - Barázar (Ceánuri, Vizcaya). Estudios del Instituto Alavés de la Naturaleza, 2: 179-199.

Infante, M. \& Heras, P. (1987b). Sphagnum imbricatum Hornsch. ex Russ, semifósil, en la turbera de Saldropo - Barázar (Ceánuri, Vizcaya). Estudios del Instituto Alavés de la Naturaleza, 2: 201-203.

Infante, M. \& Heras, P. (1988). Estudio briológico del macizo del Gorbea (Alava y Vizcaya). Estudios del Instituto Alavés de la Naturaleza, 3: 51.171.

Infante, M. (2000). Las hepáticas y antocerotas (Marchantiophyta y Anthocerotophyta) en la Comunidad Autónoma del País Vasco. Guineana, 6. 345 pp. Servicio editorial de la Universidad del País Vasco.

Peñalba, M.C. (1988). Analyse pollinique de quatre tourbières du Pays Basque espagnol. Actes Xe Symposium APLF. Bordeaux, 28 Sept. - 2 Oct. 1987. Inst. fr. Pondichéry, trav. sec. sci. tech., 25: 65-71. 
Prieto, A., Heras, P. \& Infante, M. (1999). Mapa de Vegetación del Humedal de Saldropo. Informe inédito. Asociación Saldropo. Departamento de Agricultura y Pesca. Gobierno Vasco.

Ugarte, F., García Antón, M., Ruiz zapata, B., Aseginolaza, C. \& Heras, P. (1986). Valores del patrimonio. La turbera de Saldropo. Estudio de Ordenación del Macizo del Gorbea: 110199. Departamento de Política Territorial y Transportes. Viceconsejería de Medio Ambiente. Gobierno Vasco - Aranzadi.

Uribe-Echebarría, P.M., Campos, J.A. (textos), Zorrakin, I. \& Domínguez, A. (ilustraciones) (2006). Flora Vascular Amenazada en la Comunidad Autónoma del País Vasco. Departamento Medio Ambiente y Ordenación del Territorio. Gobierno Vasco. 389 pp. 